\title{
EL EMPERADOR ESTÁ DESNUdO
}

\section{Sociofobia. El cambio político en la era de la utopía digital \\ César Rendueles \\ Capitán Swing, Madrid, 2013 \\ 206 páginas, $15 €$}

$\mathrm{C}$

Yésar Rendueles desarrolla en este ensayo una excelente propuesta de revisión epistemológica sutil de aquellas caracterizaciones de la realidad social y humana que pretenden establecerse como hegemónicas en estos tiempos convulsos. La sociofobia de la que habla supone un antihumanismo que comparten todos los ismos que pone en la picota y donde se encuentran codo con codo compañeros que uno no hubiera imaginado unidos: copyright, copyleft, burocracia, mercado, cooperación en internet, comunitarismo, formalismo, centralismo, las propuestas identitarias postmodernas, ciberutopismo, consumismo, la astenia política, el ciberfetichismo, la heteronomía, y la fragmentación de la experiencia.

Los martillazos que reparte a diestro y siniestro argumentando clara y sólidamente sus acusaciones van dirigidos a dejar en contundente evi-

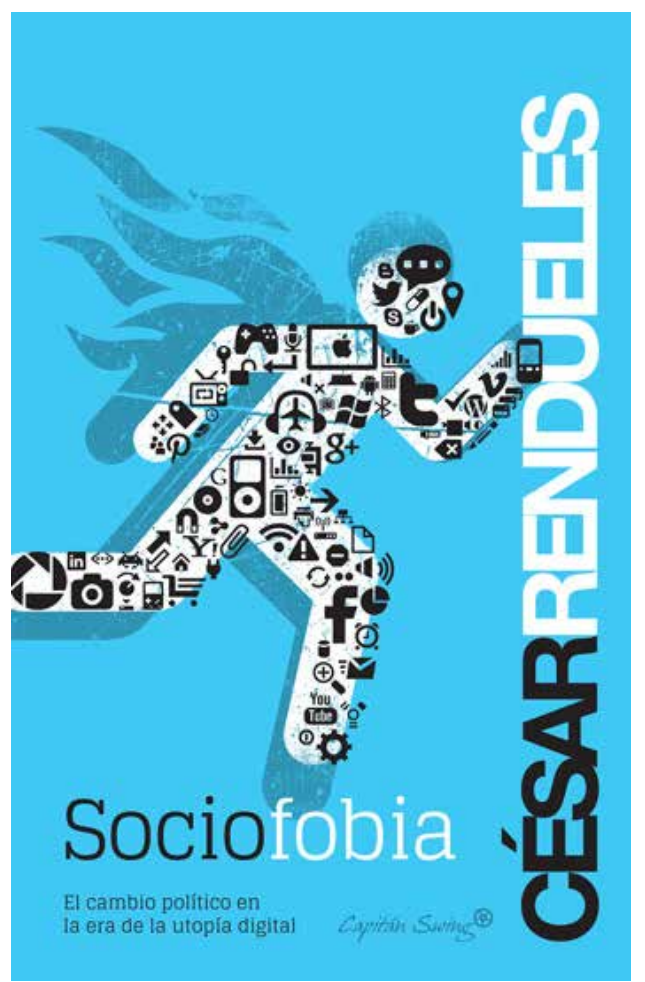

dencia la desnudez, no sólo del emperador - que en este caso sería el capitalismo por tratarse del sistema hegemónico de organización social de vocación universal y exclusivasino de todos los reyezuelos que éste ha fagocitado. No se trata de repetir aquí sus argumentaciones, tan sólo señalaré lo que me parece más suge- 
rente y lo que debería incorporarse al debate al hilo de su análisis.

En primer lugar, la denuncia de que las —así denominadas - ciencias humanas y sociales han caído desde hace muchos años - y lo hemos permitido - en un aberrante intento de identificarse con las ciencias positivas ignorando su condición praxiológica: «Se trata de conocimientos prácticos donde la experiencia, la recepción y ampliación del bagaje empírico pasado, la imaginación o la elaboración analítica resultan determinantes» (p. 156). Donde nos las tenemos que ver con sistemas complejos, abiertos y autorregulados, donde no cabe la simple agregación lineal de simplificaciones metodológicas, y donde una de las claves consistirá en tener en cuenta los contextos de toda índole. En última instancia, en las ciencias humanas y sociales no sólo tenemos que gestionar lo racional; lo claro, definido y unívoco; lo cuantitativo, etc., sino también lo irracional, confuso, difuso, ambiguo, cualitativo, etc. El papanatismo positivista en ciencias humanas y sociales ha ido generando una película alienante de la interpretación de la realidad en manos de expertos que sustrae el mundo de nuestra experiencia directa, personal y genuina. Solemos olvidar que los resultados de las investigaciones en ciencias sociales — para no hablar de su diseño y financiación- se harán servir para normalizar la realidad - tanto para justificar el estado de las cosas, como para cambiarlo- ocultando su caracterización ideológica al apelar a la supuesta neutralidad virginal de su cientificidad, o a su acotación como conocimiento experto para el que nuestra condición de ciudadano no cualifica. El reconocimiento de la fragilidad constitutiva de nuestro conocimiento no nos obliga a divagar en «narrativas» cargadas de irracionalidad poética estetizante y autoindulgente, sino a reforzar la exigencia de racionalidad y razonabilidad tanto en los procesos como en los resultados. Nuestro universo social y moral «está habitado por realidades brumosas e indeterminadas, sin límites estrictos, de las que tenemos ideas confusas, poco precisas. Estamos condenados a intervenir en ellas mediante dispositivos prudenciales continuos, y a comprenderlas mediante mecanismos explicativos contingentes» (p. 183). $Y$ reconocer nuestra incapacidad para disponer de «teorías de la realidad humana» debería ser fuente de alegría - por mantenernos en la comprensión-y alivio - por no finiquitar lo humano- - La sola introducción de 
éste giro redefiniría sustancialmente nuestra actividad.

Cabría esperar que los aparatosos fracasos de la ciencia económica en los últimos tiempos de desbaratamiento del mercado, y con la ayuda de los análisis de (entre otros) Thomas Piketty (2013) — tan denostados por el conservadurismo más feroz del ámbito cultural anglosajón - contribuyan a mostrarnos la desnudez de las ciencias humanas y sociales y nos ayuden a recuperar la exigencia de un marco de referencia ético en el que insertar nuestro estudio.

En segundo lugar, el ataque frontal al capitalismo - en particular a su formato actual de dominio del mercado y de la economía financiera - por ser fuente inequívoca de desigualdad, explotación y alienación que nos ha alejado de la norma antropológica, negando la política como búsqueda - fundamentalmente - de consenso a desarrollar por los ciudadanos, no por los expertos (científicos o tecnócratas). La cantinela históricamente machacona de la unión consustancial de capitalismo y democracia debe ser denunciada por manifiestamente falsa. El capitalismo nos quiere diferentes y necesitados, y la extensión del consumismo a todas las facetas de lo humano hasta transformarlo en una forma de estar en el mundo cumple esos objetivos a la perfección; hasta el espacio político convencional ha acabado siendo definido mercantilmente. En contrapartida, la democracia nos necesita iguales y sin que ningún asunto quede fuera de nuestra consideración. El desarrollo actual de la tecnología no resuelve los problemas de escasez o distribución — sus objetivos en el pasado- sino que genera otros nuevos o exacerba los antiguos: paro o sobreocupación, en lugar de tiempo libre; un medio de comunicación de masas tan potente como la televisión aliena y analfabetiza en lugar de ilustrar. Nos han vendido, y hemos comprado pagando un alto precio, que la desigualdad de clase no es relevante, y nos hemos hipnotizado con todos los sucedáneos de identidad de género, origen, creencia, cultura, etc., renunciando a los ideales fuertes de la ilustración y del socialismo — por no hablar de los radicales del anarquismo histórico arrinconados en la más ignorada de las utopías - y hasta parece que hayamos abandonado la búsqueda de una vida buena que ha figurado en el núcleo de nuestra cultura desde la Grecia clásica. 
En tercer lugar, la creencia ciega $\mathrm{y}$ sin posible fundamento de que la tecnología, por sí misma, es fuente de bienestar y progreso; que genera necesariamente formas sociales novedosas y liberadoras. De ahí que Rendueles hable del ciberfetichismo y de la sociofobia como «la fase final de aceptación de la heteronomía terminal moderna, cuando ya sin ira ni negación nos sometemos al mercado y tratamos de emular socialmente sus dispositivos básicos» (p. 158) (la cursiva es mía). La fragmentación de la experiencia humana; el aislamiento y la separación de la acción y las consecuencias de la acción; la desaparición de la responsabilidad; la virtualización de cada vez más ámbitos, posibilitan unos niveles de alienación y de pérdida de soberanía personal y social hace años inimaginables: aceptamos sin pestañear la destrucción de vidas humanas por medio de drones a miles de kilómetros de distancia disociadas de acciones inocentes sobre joysticks y botones en una apacible habitación en la que intentamos no hacer ruido para no despertar al hijo que duerme; igualmente, aceptamos que acciones automatizadas como consecuencia de decisiones diferenciadas por nanosegundos desde un servidor en la nube alteren los precios de las cosechas en otro continente produciendo hambrunas; ¿desde cuándo nos parece normal que se nos vendan sensaciones en vez de productos?, ¿desde cuándo una chaqueta de Prada produce una sensación distinta de una copia?, ¿o es la información añadida — propaganda/ publicidad - de que se trata del objeto genuino la que produce una sensación diferente?

Y en cuarto lugar, la necesidad de una nueva antropología que pivote sobre nuestra condición de seres humanos colectivamente codependientes y capaces de armonizar esta faceta de nuestra naturaleza con la búsqueda de la libertad personal para fundamentar una ética del cuidado mutuo. Cuidado mutuo que materialice un vínculo político racional y razonable que posibilite un nuevo contrato social en un nuevo orden postcapitalista donde recuperar la deteriorada solidaridad entre generaciones reclamada por Tony Judt como imprescindible para garantizar el bienestar y la paz sociales. Rendueles subraya la radical fragilidad de la persona para reclamar que «La emancipación y la igualdad, la libre realización en común de nuestras capacidades, no se puede desvincular del mutuo cuidado de nuestras debilidades» (p. 152). 
El aprendizaje y el entrenamiento del trabajo de cuidados sólo ocurre a partir de la empatía en contextos relacionales de proximidad asimilables a lo que en educación denominamos socialización primaria $\mathrm{y}$ que históricamente delegábamos en las familias y que ahora ninguna instancia institucionalizada asume. Afortunadamente, todavía disponemos de algo más del cincuenta por ciento de la población del planeta - las mujeres - que por naturaleza y cultura específica disponen de un ingente bagaje de recursos de toda índole para impregnar al resto de la humanidad del compromiso con el cuidado mutuo.

Evidentemente no defendemos una vuelta a un infame pasado de discriminación y abuso sino una revolución como la que proponía Agustín García Calvo en 1977 para que la especificidad de la mujer destruyera el Estado. Y hacerlo con el sentido de la responsabilidad social que Rendueles reclama en el cierre de su ensayo: «La democracia no se puede fragmentar en paquetes de decisiones individuales porque tiene que ver con los compromisos que nos constituyen como individuos con alguna clase de coherencia, con un pasado y alguna remota expecta- tiva de futuro. Y ésta es una realidad antropológica incompatible con el ciberfetichismo y la sociofobia» (p. 187).

Desnudo total.

Paco Marco, Universitat Jaume I

\section{Bibliografía}

García Calvo, A. (1977): Qué es el estado. La Gaya Ciencia, Barcelona.

JudT, T. (2010): Algo va mal. Taurus, Madrid.

PIKetTy, T. (2013): Le capital au XXIe siècle. Éditions du Seuil, Paris, 2013 (El capital en el siglo XXI. De próxima publicación en Fondo de Cultura Económica). 
